\title{
ADENOID CYSTIC CARCINOMA INVOLVING MAXILLARY SINUS: REVIEW AND CASE REPORT
}

\author{
Viswanathan Narayanan ${ }^{1}$, Bhaskara M. N², Raji R. Pillai³, Nanoo Prathibha Sivaprasadan ${ }^{4}$
}

\section{HOW TO CITE THIS ARTICLE:}

Viswanathan Narayanan, Bhaskara M. N, Raji R. Pillai, Nanoo Prathibha Sivaprasadan. "Adenoid Cystic Carcinoma Involving Maxillary Sinus: Review and Case Report". Journal of Evolution of Medical and Dental Sciences 2014; Vol. 3, Issue 42, September 08; Page: 10463-10468, DOI: 10.14260/jemds/2014/3363

ABSTRACT: Salivary gland tumors of Para nasal sinuses are relatively uncommon. They are classically slow growing, with patients being aware of their presence over months or even years. The reported incidence is approximately $3 \%$ of all head and neck neoplasms. Tumors of minor salivary gland origin account for only $10-15 \%$ of all salivary gland neoplasms. Adenoid cystic carcinoma accounts for $21 \%$ to $42 \%$ of minor salivary gland tumors and occurs most frequently on the hard palate, rarely it involves the maxillary sinus causing worsening of its prognosis. This cancer is characterized by its infiltrative growth and perineural invasion. Surgery followed by radiotherapy remains to be the gold standard to treat this carcinoma. We present a case of adenoid cystic carcinoma involving the maxillary sinus in a 45 year old female patient and brief review of the literature for adenoid cystic carcinoma in terms of its biological nature, the histogenesis, pattern of spread and the treatment modalities.

KEYWORDS: carcinoma, adenoid cystic carcinoma, salivary glands.

INTRODUCTION: Minor salivary gland tumors (benign and malignant) are a rare clinical entity.[1] Salivary gland carcinomas (major and minor) represent around 3 per cent of all head and neck malignancies.[2] Minor salivary gland tumors represent a heterogeneous group of neoplasm, with a broad range of histological types and growth patterns. Tumors originating in the minor salivary glands are infrequent, and represent less than $20 \%$ of all salivary neoplasms.[3] They are usually innocuous, asymptomatic and do not interfere with function till they attain large size.

On the basis of appearance alone, it is not possible to differentiate between benign and malignant variants. The overlying mucosal ulceration is generally only secondarily, from either masticatory or denture trauma or pressure.[4] Age plays very little role in differential diagnosis of minor salivary gland neoplasia, as these lesions can arise at any age.

Outcome of treatment of minor salivary gland carcinoma is closely related to the histological type and surgery followed by radiation treatment yield better control of local disease than either surgery or radiation alone. ${ }^{[5]}$ We present a case of adenoid cystic carcinoma in a 45 year old female patient reported to our institution (AZEEZIA MEDICAL COLLEGE, KERALA) and review the literature for this carcinoma.

CLINICAL FEATURES: Salivary glands most commonly involved by adenoid cystic carcinoma are parotid, sub maxillary and accessory gland in the palate and tongue. This tumor occurs most commonly during the $5^{\text {th }}$ and $6^{\text {th }}$ decades of life. It is more common in females.

Many of the patients exhibit clinical manifestation of early local pain, fixation to deeper structures, local invasion. The intra oral lesion may exhibit surface ulceration. 
Adenoid cystic carcinoma has a marked tendency to spread through perineural spaces and usually invades well beyond the clinical apparent borders.

CASE REPORT: A 45 year old female patient reported to our institution (AZEEZIA MEDICAL COLLEGE, KERALA) with a chief complaint of left sided facial pain for last one month. On clinical examination, intra orally there was tenderness on palpation in relation to left gingivo buccal sulcus. Personal history of the patient in terms of deleterious habits was not significant.

Patient was advised for a CT scan (Figure-1) which showed radio opaque lesion involving the left maxillary sinus anteriorly extending from canine -premolar area till posteriorly molar region with bony erosion and superiorly involving more than two- third of maxillary sinus. A radiological diagnosis of malignancy was reported.

Incisional biopsy was done by an intraoral Caldwell luc operation under GA which confirmed the clinical and radiological diagnosis of malignancy. Histopathological diagnosis of adenoid cystic carcinoma from the minor salivary glands was reported. (Figure-2) Solid pattern is seen prominently in the histological section which suggests histological diagnosis as solid variant of adenoid cystic carcinoma. It also revealed perineural invasion of tumor cells which is the characteristic of this tumor.

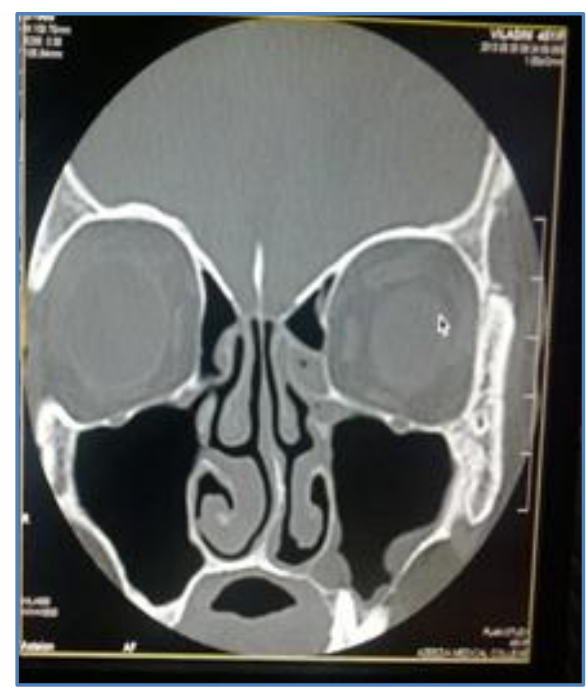

Fig. 1

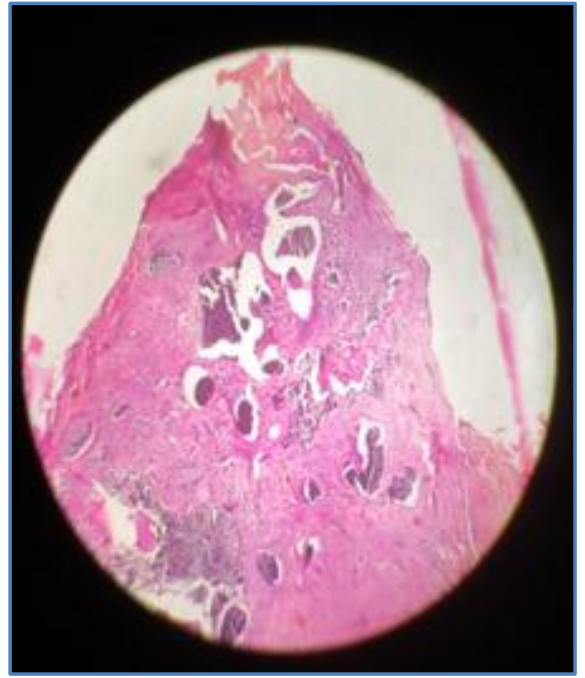

Fig. 2

Weber Fergusson approach: A standard approach for partial or total maxillectomy was used in this case incision begin in the midline of upper lip through philtrum up to collumella of nasal cavity, curving around the nasal vestibule and ala of nostril up to the nasolabial crease up to the medial canthus. Upper lip is divided through its full thickness up to gingivolabial sulcus.

To elevate the upper cheek flap an incision is made in the mucosa of upper gingivobuccal sulcus the flap is elevated in full thickness to expose the maxilla. Total Maxillectmoy was done, bone cuts made with bur, osteotomes later. Pterygoid disjunction was done to remove the affected maxilla. Prosthetic rehabilitation was done with an obturator to seal the oro nasal communication.. Wound was closed in layers. 


\section{CASE REPORT}

\section{INTRA -OPERATIVE PHOTOS}
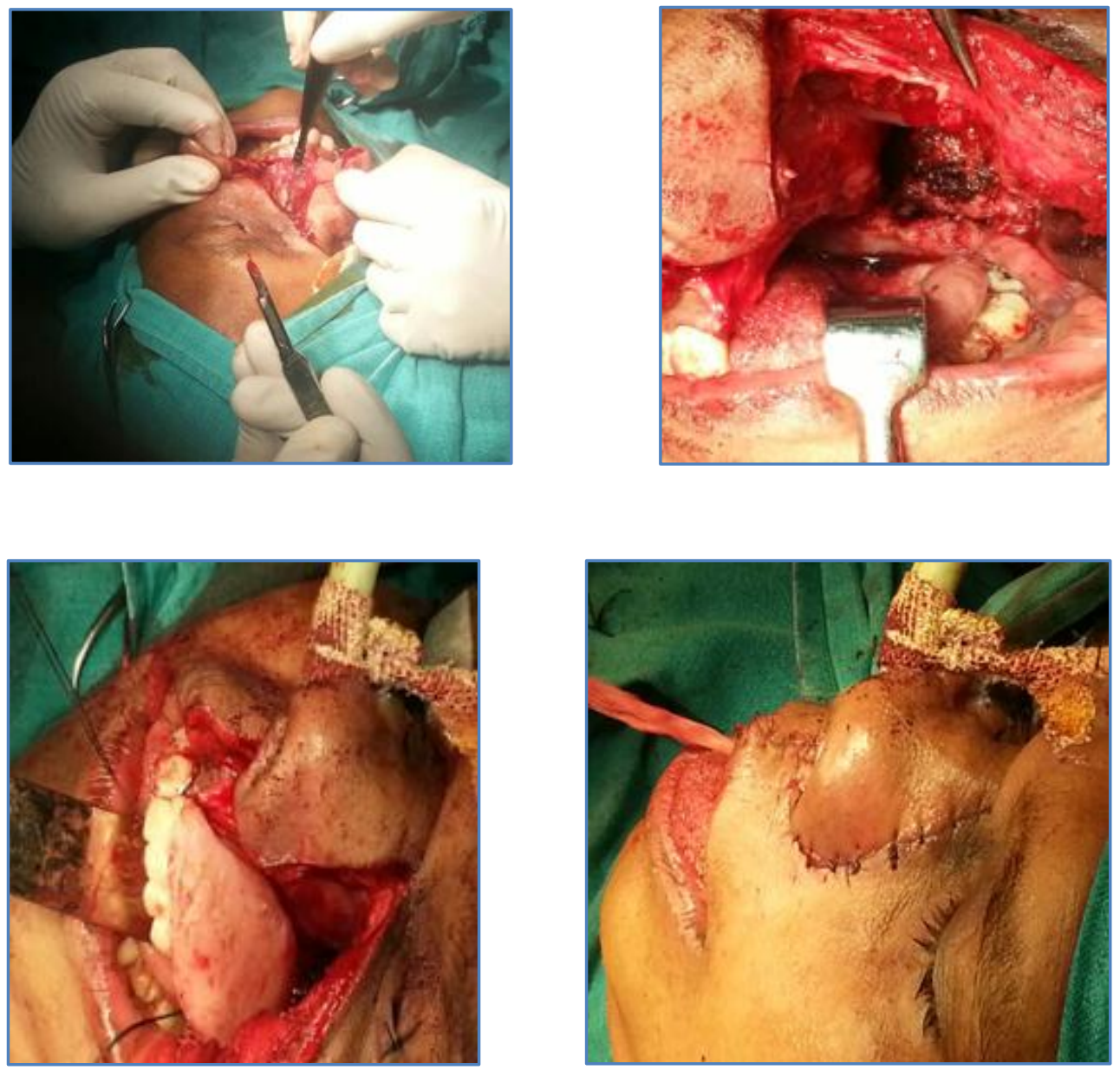

Post-operative follow up was done in first, second and third week. Post-operative radiation was given at fourth week. Sixth month and first year follow up was done. No recurrence of lesion was reported. Strict follow up will be followed in future as the histological variety reported was solid variety, which was associated with the highest incidence of recurrence.

DISCUSSION: Adenoid cystic carcinoma accounts for $21 \%$ to $42 \%$ of minor salivary gland cancers and occurs most frequently on the hard palate. It is characterized by its infiltrative growth and perineural invasion. Spread to regional lymphatics is relatively uncommon, but hematogenous spread occurs in $25 \%$ to $50 \%$ of cases which directly affects the prognosis. Systemic involvement is said to occur in the presence of uncontrolled disease at the primary site.[6]

The three major subtypes of adenoid cystic carcinoma are cribriform, tubular, baseloid or solid variants.[7] The baseloid solid pattern is characterized by solid nests or sheets of cells representing areas of anaplastic tumor and carries worst prognosis.[8]

Several studies for adenoid cystic carcinoma have been reported in the literature elaborating the biologic nature, histogenesis, metastatic spread, treatment modalities for this tumor. Chaudhry AP et al., in 1986 studied 12 cases of adenoid cystic carcinoma using light and electron microscopy 
and found the presence of myoepithelial cells in 9 out of 12 cases representing the histogenesis of this tumor. [9] Takakashi $\mathrm{H}$ et al., in 2004 reviewed 200 cases of intraoral minor salivary gland tumors of which 73 were malignant.

They reported adenoid cystic carcinoma as the most common malignant tumor with palate as the common site and mean age of occurrence as 47.2 years for females and 50.6 years for males.[10] Garden AS et al., studied the influence of positive resection margins and nerve invasion in 198 patients of adenoid cystic carcinoma. They stated that perineural invasion is associated with an increased rate of local failure. ${ }^{[11]}$

Regezi JA et al., evaluated the clinical, histological and immuno histochemical data on 238 oral minor salivary gland tumors and concluded that adenoid cystic carcinomas stained positive for S-100 protein. ${ }^{[12]}$ This finding of S-100 protein in adenoid cystic carcinoma is a helpful differentiating feature when canalicular adenoma is multifocal.

Avery CME et al., in their retrospective study of 15 cases of adenoid cystic carcinoma reported the influence of combined treatment on adenoid cystic carcinoma and concluded that combination treatment with both surgery and radiotherapy has improved the control of local disease.[13] Beckhardt RN et al., reviewed 116 malignant minor salivary gland tumors over a period of 46 years and stated that grade 3 tumor histology, tumor size greater than $3 \mathrm{~cm}$, perineural invasion, bone invasion and positive surgical margins were associated with decreased survival.[14]

Salivary gland tumors are known for late recurrences.[15] In case of adenoid cystic carcinoma, which has a distinctive clinical and histological pattern of behavior, the rate of recurrence is relatively high. The margins of the tumor are usually ill-defined; with narrow columns of cells streaming off from the main mass along the tissue planes between specialized structures such as muscle fasciculi, and most markedly along perineural spaces.

Perineural spread is noted microscopically in approximately two-thirds of patients with adenoid cystic carcinoma of the minor salivary glands. ${ }^{[16]}$ The absence of host lymphocytic reaction to tumor cells, the frequency of "skip areas" with clumps of cells permeating the tissue beyond the apparent edge of the tumor, between muscle fibers, in Haversian systems makes the margins of clearance extremely difficult.

Adenoid cystic carcinoma is a characteristic tumor of minor salivary glands with most common site of occurrence in the hard palate, with the involvement of maxillary sinus causing worsening of its prognosis. A combination of surgery followed by radiotherapy is highly recommended to control the local disease and limit distant metastasis.

CONCLUSION: Orofacial pain is one of the common symptom and requires great skill to identify the actual pathology. The adenoid cystic carcinoma involving the maxillary sinus without any visible lesion over the palate is quite rare.

Diagnosis should be made with clinical and radiological evaluation and confirmed by tissue biopsy. Total maxillectomy with post-operative radiotherapy is the preferred mode of treatment. Regular follow up is very important as these tumors are very aggressive and recurrence rates are high. 


\section{REFERENCES:}

1. Hyam DM, Veness MJ, Morgan GJ. Minor salivary gland carcinoma involving the oral cavity ororopharynx. Aust Dent J, 2004; 49: (1): 16-19.

2. Vicente OP, Marqués NA, Aytés LB, EscodaCG. Minor salivary gland tumors: A clinicopathological study of 18 cases. Med Oral P Patol Oral Cir Bucal 2008; 13 (9): E582-8.

3. Jansisyanont P, Blanchaert Jr RH, Ord RA. Intraoral minor salivary gland neoplasm: a single institution experience of 80 cases. Int. J. Oral Maxillofac. Surg. 2002; 31: 257-261.

4. MacIntosh RB. Minor salivary gland tumors: types, incidence, and management. Oral Maxillofac Surg Clin N Am 1995; 7: 573-89.

5. Chou C, Zhu G, Luo M, Xue G. Carcinoma of the Minor Salivary glands: Results of surgery and combined therapy. J Oral Maxillofac Surg 1996; 54: 448-53.

6. Anderson JN, Beenken SW, Crowe R, Soong SJ, Peters G, Maddox WA, Urist MM. Prognostic factors in minor salivary gland cancer. Head Neck 1995; 17: 480-86.

7. Brookstone MS, Huvos AG, Spiro RH. Central adenoid cystic carcinoma of the mandible. J Oral Maxillofac Surg 1990; 48: 1329-33.

8. Mc Gregor IA, Mc Gregor FM. Salivary Tumors. Cancer of the face and mouth; Churchill Livingstone, Edinburgh 1986; 569-606.

9. Chaudhry AP, Leifer C, Cuter LS, Satchidanand S, Labay GR, Yamane GM. Histogenesis of adenoid cystic carcinoma of the salivary glands: Light and Electron microscopic study. Cancer 1986; 58: 72-82.

10. Takahashi H, Fugita S, Tsuda N, Tezuka F, Okabe H. Intraoral minor salivary gland tumors: a demographic and histologic study of 200 cases. Tohoku J Exp Med 1990; 161: 111-28.

11. Garden AS, Weber RS, Morrison WH, Ang KK, Peters LJ. The influence of positive margins and nerve invasion in adenoid cystic carcinoma of the head and neck treated with surgery and radiation. Int J Radiat Oncol Biol phys 1995; 32 (3): 619-26.

12. Regezi JA, Lloyd RV, Zarbo RJ, Mc Clatchey KD. Minor salivary gland tumors: A histologic and immunohisto chemical study. Cancer 1985; 55: 108-15.

13. Avery CME, Moody AB, McKinna FE, Taylor J, Henk JM, Langdon JD. Combined treatment of adenoid cystic carcinoma of the salivary glands. Int J Oral Maxillofac Surg 2000; 29: 277-79.

14. Bechardt RN, Weber RS, Zane R, Garden AS, Wolf P, Carrrillo R, Luna MA. Minor salivary gland tumors of the palate: Clinical and pathologic correlates of outcome. Laryngoscope 1995; 105(11): 1155-60.

15. Garden AS, Weber RS, Ang KK, Morrison WH, Matre J, Peters LJ. Postoperative radiation therapy for malignant tumors of minor salivary glands. Cancer 1994; 73(10): 2563-69.

16. Parsons JT, Mendenhall WM, Stringer SP, Cassisi NJ, Million RR. Management of minor salivary gland carcinomas. Int J of Radiat Oncol Biophys 1996; 55: 443-54. 


\section{CASE REPORT}

\section{AUTHORS:}

1. Viswanathan Narayanan

2. Bhaskara M. N.

3. Raji R. Pillai

4. Nanoo Prathibha Sivaprasadan

\section{PARTICULARS OF CONTRIBUTORS:}

1. Professor and HOD, Department of ENT, Azeezia Medical College and Hospital, Kollam.

2. Associate Professor, Department of ENT, Azeezia Medical College and Hospital, Kollam.

3. Assistant Professor, Department of ENT, Azeezia Medical College and Hospital, Kollam.

4. Assistant Professor, Department of ENT, Azeezia Medical College and Hospital, Kollam.

\section{NAME ADDRESS EMAIL ID OF THE} CORRESPONDING AUTHOR:

Dr. Viswanathan Narayanan, Professor and HOD, Azeezia Medical College and Hospital, Kollam.

Email: ent.viswas@gmail.com

Date of Submission: 25/08/2014. Date of Peer Review: 26/08/2014. Date of Acceptance: 03/09/2014. Date of Publishing: 06/09/2014. 